\title{
COVID-19: IMPACT OF THE PANDEMIC ON THE SUSTAINABLE DEVELOPMENT GOALS
}

\author{
Ammar Samout ${ }^{* 1}$ 两, Boutheina Marnissi 2 四 \\ ${ }^{* 1}$ Department of Management Science, Faculty of Economics and Management of SFax- Tunisia. \\ ${ }^{2}$ Laboratory of Epidemiology and Veterinary Microbiology, Institute Pasteur of Tunis, University \\ Tunis El Manar, Tunis, Tunisia
}

DOI: https://doi.org/10.29121/IJOEST.v4.i5.2020.117

Article Type: Research Article

Article Citation: Ammar Samout, and Boutheina Marnissi. (2020).

COVID-19: IMPACT OF THE

PANDEMIC ON THE SUSTAINABLE

DEVELOPMENT GOALS.

International Journal of Engineering

Science Technologies, 4(5), 51-59.

https://doi.org/10.29121/IJOEST.v

4.i5.2020.117

Received Date: 5 August 2020

Accepted Date: 28 September 2020

Keywords:

Covid-19

Health Crisis

Sustainable Development Goals

\section{ABSTRACT}

In this article, we are interested in what extent and how the COVID-19 health crisis affects the goal of sustainable development.

So, after defining the concept of sustainable development and its pillars, this article recommends evaluating the impact of the health crisis on the sustainability of development.

And to answer this question, we chose a method that involves first reviewing the theoretical literature on the subject and then continuing to study the impact of COVID-19 on many sustainable development goals.

\section{INTRODUCTION}

The health crisis of covid-19 has evolved into a pandemic, triggering an unprecedented global economic crisis.

This crisis has raised questions about the stability of the balance to ensure world food security. Today's production and consumption patterns are questionable.

This epidemic highlights the existing weaknesses and inequalities in the health system, as well as the agricultural and food systems.

The extent of the crisis is difficult to predict, but it will inevitably have a negative impact on our national economy. According to the latest estimates of the International Monetary Fund, the crisis identified by the World Health Organization as a "major global health crisis of the current era" will cause losses to the world economy, and there will be three quarters of growth points by 2020, mainly due to Due to confinement.

More than 3 billion residents and borders closed.

« Tunisia will be strongly affected by the coronavirus pandemic. Its impact on the national economy will be serious. ». "This is especially the International Monetary Fund's (IMF) imagination of Tunisia's economic situation in 2020.

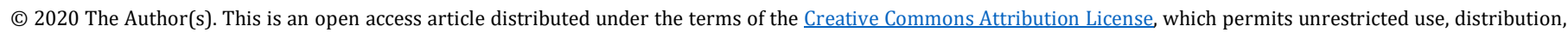
and reproduction in any medium, provided the original author and source are credited. 
Today's sustainable development is in a situation that can be described as difficult, without falling into pessimism to describe it as a crisis like them (2014: 2).

Indeed, despite the efforts of institutions and media so far, the expected goals have not been achieved, and the results are still negative: degradation of the biosphere, global warming, increasing world poverty, etc.

The Covid-19 global pandemic severely affected the 17 Sustainable Development Goals.

Starting from a local health crisis, the Covid-19 pandemic has become a global economic and social crisis in record time. It dramatically shows the interdependence of the three pillars of sustainable development: environment, society and economy, and the need to change our production patterns and lifestyles. In order to achieve this goal, there is an analysis grid: the grid of the Sustainable Development Goals (SDG) adopted by the United Nations in 2015, which shows that it is important for understanding crises and achieving a more sustainable future.

Therefore, the sustainable development of the medical field must be determined as the desire to improve the quality of life of patients and nursing staff.

According to the 2002 "Johannesburg Declaration", the World Health Organization (2002) strongly emphasized the importance of putting human beings at the center of concern related to sustainable development, which is the basis for protecting and promoting human health.

The two areas of public health and sustainable development should be introduced to illustrate how these two components overlap and merge.

Then, we will study the effects of various hospital reforms. Although legal, such mutations in the medical system can sometimes prove incompatible with long-term prospects.

\section{DEFINITION OF SUSTAINABLE DEVELOPMENT}

Sustainable development is a type of respect for economic, social and environmental development.

It is also about respect for future generations and the needs of the most vulnerable groups.

Like all theories related to economic thought, sustainable development has gone through a long process, and then it has been systemized and accepted by the international community as the development model of the end of the century and the coming.

There are several definitions of sustainable development:

- The most famous definition of sustainable development is the definition in the Brundtland Report in 1987: "Sustainable development means striving to meet current needs without compromising the ability to meet future generations."

- $\quad$ "If development can guarantee to meet the needs of all countries and all populations for contemporary people, without compromising the possibility of future generations meeting their needs and protecting biodiversity, then development is sustainable."

The first sentence says: "Man has the right to basic freedom, equality and satisfactory living conditions. In such an environment, its quality enables him to live with dignity. It is solemn to protect and improve the environment for present and future generations. responsibility......"

The second principle is: "For the benefit of contemporary times, we must protect global resources, including air, water, earth, plants, and animals, especially representative samples of natural ecosystems, and conduct careful planning or management as needed."

In these two principles, we have discovered an important connection between the definition of sustainable development proposed in the Brandland Report, that is, "meeting the needs of contemporary people without compromising the ability of future generations to meet their offspring. "

This new model attempts to reconcile economic efficiency, social progress, and ecosystem protection by establishing a benign connection between these three areas.

The main goals of sustainable development include:

- protect environment.

- Social equality and poverty reduction.

- Preservation and regeneration of ecological resources. 
- Improve economic efficiency.

- Incorporate environmental themes into policies, planning and management, market incentives and accounting.

- Promote sustainable production/consumption methods.

\section{THE PILLARS OF SUSTAINABLE DEVELOPMENT} 1).

Sustainable development considers three indivisible aspects: economy, society and environment (see Figure

This means that economic development must meet human needs and promote wealth creation for all through sustainable production and consumption methods. The social dimension aims to meet human needs (housing, healthcare, education, etc.). The third point concerns the protection and improvement of the environment, especially through the rational use of natural resources and prevention of environmental impact.

Therefore, the goal is to find a balance between these three pillars:

- Economy: We must promote a responsible economy and incorporate environmental and social principles into the feasibility of the project.

- Environment: Natural resources are not unlimited; the focus here is to protect natural resources. Social: Integrate social aspects in global terms from both internal and external perspectives of the company. This often-overlooked concept must be seen as a whole.

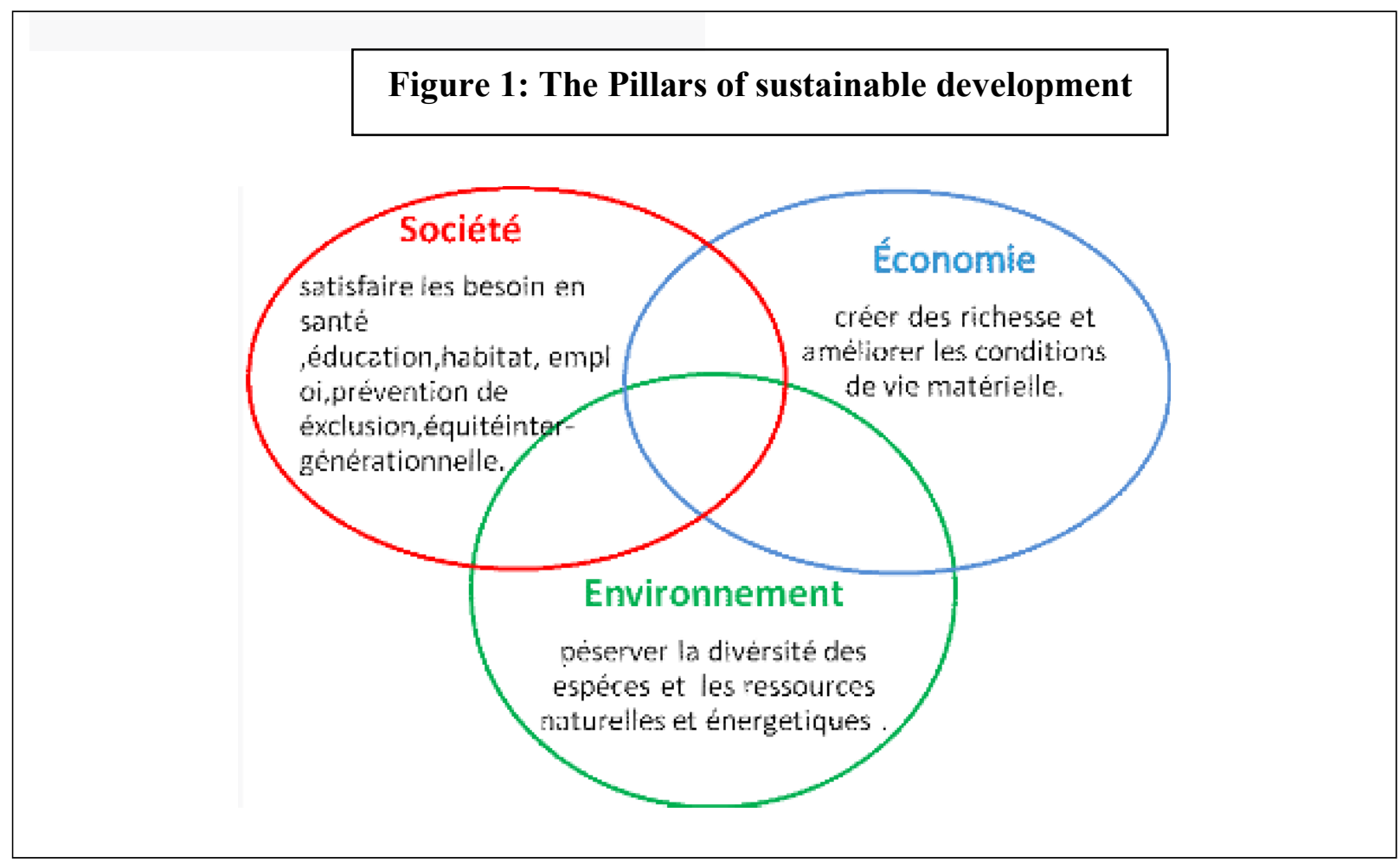

Source: Bolivar ${ }^{1}(2008, \mathrm{p} 26)$

The United Nations World Commission on Environment and Development called sustainable development "sustainable development is a form of development that meets current needs without compromising the ability of future generations to meet their needs" (1987, p. 51).

${ }^{1}$ Bolivar J.G. (2008). How to integrate environmental and development issues into all methods of project management: a conceptual approach to the project planning model based on a logical framework method. Uka 
The foundation of the social level is the establishment of housing for everyone, the means of survival, but the most important thing is access to education and health care. This is the main product of the country and society mentioned by J. Rawls in 1971. Dimension tends to provide all necessary commodities for the sustainable development of the population. The social dimension of the sustainable development approach is aimed at combating the exclusion of individuals and establishing a fair system.

The economic level tends to promote fair relationships and exchanges. From this perspective, this is a problem, which is to look at investment in the long-term and to maximize the distribution of growth results.

Environmental aspects are often related to natural resources. However, from the perspective of sustainable development, it is necessary to increase personal knowledge and skills. The role of human capital goes far beyond the pure and unique ecological dimension, and it is closely related to other dimensions previously identified.

These three pillars together constitute the concept of sustainable development, which is essential for understanding the overall concept of sustainable development (A. Dahlsrud, 2008). The moral, ethical and fair values of sustainable development lay the foundation for these three pillars. Therefore, sustainable development aims to improve personal conditions in terms of quality and quantity.

Therefore, the integration between public health and sustainable development is real, and even inevitable, because it is part of a long-term perspective that respects environmental, social and economic factors. Sustainable development is an integral part of the joint construction of public health and national unity (WHO, 2001; 2002).

From a sustainable perspective, investment in public health has become a catalyst for a country's economic development, helping to reduce poverty and inequality. Applied to sustainable development, the three pillars that constitute this concept can be determined as follows:

- The social dimension of the public health field is related to the way of education of the individual. Therefore, it promotes discussions about healthy choices and the contributions necessary to maintain a healthy life. Likewise, interpersonal communication and social relations are essential to maintain the best possible life, the ability to promote change and therefore consider the best health technology.

- The economic aspect is the basis for health measures. Therefore, the income level, which is often related to social status and education level, affects the consideration of health risks. The more likely a person is in an unstable state (such as unemployment or underemployment), the more likely it is to suffer from higher medical and health risks. For INSEE (2011), the link between health and social status is obvious: "Executives belong to a social group whose lifestyle is conducive to health: high-risk health behaviors, fewer requests for help and access to care or obese workers Than managers" (Insee, 2011, p. 2).

- The environmental dimension is also closely linked to the state of people's health. The state of the physical environment has a major impact on the health of populations. Degradation of the components of the biosphere has an impact on species and on the fate and survival of individuals (Health Canada, 2005). Climate change (tropical storms, droughts) have an impact on the natural environment and consequently on the determinants of health (chronic or acute respiratory diseases, cancers and melanomas caused by ultraviolet rays, etc.). For Health Canada (2004), "the impacts of climate change on health and society will vary by region and will result in significant costs [...] including increased health care spending, reduced productivity and marked reductions the well-being of its citizens" Health Canada (2004, p 20).

\section{IMPACT OF THE HEALTH CRISIS ON SOME SUSTAINABLE DEVELOPMENT OBJECTIVE}

The COVID-19 pandemic is a test for mankind. But it also gives it an opportunity to express its solidarity and turn this crisis into a global driving force for achieving sustainable development goals. The figure on the right highlights the impact of these on each SDG.

The Sustainable Development Goals (SDGs), also known as global goals, are global actions called for eradicating poverty, protecting the planet and ensuring that all people live in peace and prosperity.

All 17 Sustainable Development Goals are integrated-recognizing that interventions in one area will affect outcomes in other areas, and development must balance social, economic and environmental aspects. 
The pandemic's impact on the 17 Sustainable Development Goals affects all countries. "The health crisis of the United Nations has rapidly evolved into the most serious human and economic crisis of our time, and it has begun since then," UN Secretary-General Antonio Guterres emphasized, The SDG annual update report in April 2020.

\section{Goal 1: No poverty}

Once this crisis is overcome, "the recovery must not be done on the backs of the poorest - and we cannot create a legion of new poor," assured Mr. Guterres, welcoming social protection measures, "as donations in cash or universal income", taken by some countries to help vulnerable populations.

The health crisis leads to an economic crisis. This means that efforts to fight poverty will come to a halt. As a result, the number of people affected by poverty would increase if nothing is done.

\section{Goal 2: "Zero" hunger}

Due to the pandemic of certain protection measures, the fight against hunger in the world will be greatly slowed down. Indeed, people around the world are calling for people to stay at home, borders, markets, etc. are closed. The supply and availability of food are threatened. This will affect food and nutrition security.

COVID-19 is expected to continue to increase food insecurity. In 2018, this scourge affected $26.4 \%$ of the world's population, or 2 billion people, compared to $23.2 \%$ in 2014 .

Along with conflicts, climate shocks and locust plagues, the pandemic poses another threat to the food system because it reduces the purchasing power of the most vulnerable people and their ability to produce and distribute food.

\section{Goal 3: Good health}

The World Health Organization (WHO) warned on Tuesday that the epidemic is "accelerating." It took 67 days to reach 100,000 from the first reported case, 11 days to reach 200,000 , and only four days to reach 300,000 . In more than 50 countries and regions, more than 1 billion people are required to stay at home.

The Covid-19 pandemic has "kneeled" the global health system. The rapid spread of this disease has put pressure on the health systems of several countries in the world, and countries that are already fragile have seen their health systems collapse.

\section{Goal 4: Quality Education}

The health crisis has caused many schools to close and hurt many students. Distance learning may not be as effective or even unavailable for some people.

As schools and universities closed in September, as of Wednesday, more than 1.25 billion children and young people (three-quarters of the world's school-age population) were no longer able to use their educational institutions. National plans for 124 countries/regions and many other countries/regions.

COVID-19 is also seriously damaging the quality education of SDG\#4. The suspension has prevented $90 \%$ of the world's students (1.57 billion children and adolescents) from attending classes, further depriving more than 370 million people of nutritional essentials. Distance learning solutions are provided in four-fifths of countries/regions, and this is still out of reach for the approximately 500 million schoolchildren and students who have little or no access to computers and the Internet at home.

In most countries, schools and universities have closed. Millions of young people have been urged to stay at home. In some countries/regions, online courses have been developed to enable these young people to continue training at a distance. In other parts of the world, systems and methods do not allow this. Young people just stay at home for a few months without any form of formal education, let alone quality.

\section{Goal 5: Gender equality}

Several repercussions have been observed: over-exposure to Covid-19 due to the over- representation of women in the fields of health and social services, threats to income linked to economic activity, increase in domestic violence.

The pandemic has social consequences that primarily affect women. Globally, they represent 70\% of workers in the health and social services sector and are therefore particularly exposed to the risk of contamination.

Most women who are not working or active in the informal economy are directly affected by the pandemic. In developing countries, the main economic activities of women, especially small businesses, are threatened. This leads 
to women's uneven exposure to the effects of the disease. Therefore, seeking gender equality will face the impact of this epidemic.

Despite the progress made through international commitments, this pandemic has moved further away from the goal of achieving Sustainable Development Goal 5, which aims to achieve gender equality and empower all women and girls.

Today, due to the closure of schools and nurseries, women may not only take care of most of the children, but they are also on the front line in the fight against the coronavirus. They account for nearly $70 \%$ of the world's health workers and social workers.

\section{Goal 6: Clean water and sanitation}

The United Nations and governments around the world have reaffirmed the importance of soap and water in fighting the Covid-19 virus. Despite this, it is estimated that about 2.2 billion people do not have access to safe drinking water, and 4.2 billion people (more than

half of the world's population) are deprived of sanitation systems. According to the latest report of the United Nations Water Mechanism, it is safe. Due to climate change, this situation may worsen and make achieving Goal 6 more difficult.

\section{Goal 8: Decent work and economic growth}

During the Covid-19 pandemic, SDG 8 for "decent work and economic growth" is one of the most tested SDGs. In fact, the International Labor Organization (ILO) estimates that the economic crisis caused by the pandemic could lead to an increase in unemployment of up to 25 million people worldwide. It should also be pointed out that the significant decline in workers' income is obvious, which will certainly lead to a decline in world economic growth COVID-19 has also had a very strong impact on underemployment and unemployment, undermining the decent work of Sustainable Development Goal 8 and sustained and inclusive economic growth. According to the International Labor Organization (ILO) report, as the world is facing the worst economic recession since the Great Depression, the crisis has caused the loss of 400 million full-time jobs in the second quarter of this year.

The International Labor Organization (ILO) estimates that the economic crisis caused by the pandemic may increase the number of unemployed people worldwide by as much as 25 million. It also predicts that the decline in workers' income may reach $\$ 3.4$ trillion.

\section{Goal 10: Reduce inequality}

If we take the right steps, recovery will take a more sustainable and inclusive path. However, if policy coordination is not effective, already unsustainable inequalities may become entrenched and exacerbated," the UN Secretary-General warned.

\section{Goal 11: Sustainable cities and communities}

The Sustainable Development Goal 11 concerning inclusive, safe, resilient and sustainable human settlements has also been attacked by COVID-19, with more than $90 \%$ of cases reported in urban areas. Currently, more than 1 billion slum dwellers worldwide are threatened by a pandemic. In addition to a lack of decent housing, these people often do not have running water, and do not have proper sanitation and waste management systems. They still have no access to official health care facilities.

\section{Goal 13: Fight against climate change}

SDG 13 does not benefit from the commitments required at the global level. 2019 was the second hottest year on record, ending the hottest decade in history with an increase in wildfires, hurricanes, droughts, floods and other climatic disasters. At the current rate, temperatures are expected to increase by $3.2^{\circ} \mathrm{C}$ by the end of the century, far from the maximum target of $1.5^{\circ} \mathrm{C}$ - or even $2^{\circ} \mathrm{C}$ - advocated in the Paris Climate Agreement.

To achieve this target, it is imperative that greenhouse gas emissions begin to decline $7.6 \%$ each year from 2020 . However, despite the drastic reduction in human activity due to the COVID crisis- 19 , the $6 \%$ drop now planned for 2020 falls short of this target. In addition, emissions start to rise again as restrictions are lifted 


\section{Goal 14: Life on Earth}

Through activities aimed at promoting an inclusive, diversified and productive rural economy, especially in the field of agricultural entrepreneurship, as well as the links between urban and rural areas. The coronavirus has made this situation worse.

\section{Goal 16: Peace, justice and strong institutions}

The most significant progress has been made in achieving the Sustainable Development Goals of "peace, justice and strong institutions". The coronavirus shows that people are no longer safe and the number of deaths caused by homicides and attacks has increased. Crime, violence and vandalism have also increased

\section{Goal 17: Partnership to achieve goals}

The coronavirus shows that there is a lack of effective partnerships between global, regional, national and local governments, the private sector and civil society.

It also emphasizes the horizontality and interrelationship between different SDGs:

the consequences of one SDG may have a negative impact on another SDG. For example, the consequences of the health crisis on SDGs 4 and 5 have affected the achievement of SDG 10, which aims to reduce inequality.

To achieve the targets of the Sustainable Development Goals by 2030, countries must maintain their gains and step up their efforts in favor of access to affordable, reliable, sustainable and modern energy for all

The crisis highlights the absolute need to work on one of the pillars of these SDGs: the partnership between all economic actors, public and citizens, around the world. However, if a certain solidarity between actors has indeed been put in place at the local and national level, the pandemic has also shown a glaring deficit of international solidarity. And if the consequences are already being felt in Western countries, it could be fatal for developing countries, especially in Africa which is about to suffer the ravages of Covid19.

\section{TAKE AN INCLUSIVE, SUSTAINABLE AND INNOVATIVE APPROACH}

Although the pandemic has a clear impact on the Sustainable Development Goals, some interesting initiatives are still being developed around the world. For example, these are innovative forms of solidarity, humanitarian leap, etc. In some countries, medical students voluntarily provide support in crowded hospitals. Other students provided masks, hydroalcoholic gels, artificial respirators, etc.

Various countries and international organizations have formulated ambitious response plans. Through the distance learning mechanism, they donated basic necessities, paid for electricity and electricity bills, and spared no effort. All these solidarity actions promote and require lasting partnership, which is an essential element for contributing to the achievement of the Sustainable Development Goals.

In order to better accomplish these tasks, it seems important to move towards inclusive, sustainable and innovative approaches together. This requires some prerequisites, especially:

- Put science at the core of all development actions.

Development actions must better integrate scientific advice. Evidence is an effective decision- making tool. Therefore, special attention should be paid to considering scientific evidence and multidisciplinary in the decision-making process.

- Make full use of the potential of technology and innovation.

Technology and innovation are important catalysts for achieving the Sustainable Development Goals, especially during and after the Covid-19 pandemic. Indeed, technology and innovation make it possible to maintain the pace of development, and even accelerate the pace of development in some cases. The use of the Internet and artificial intelligence are examples.

- Strengthen the planning mechanism.

Without a good planning mechanism, any development is unsustainable. The implementation of the Sustainable Development Goals, without exception, should now be based more on good plans at the global, regional, national and all local levels.

- Include more young people and women in all initiatives. 
Women and young people make up the majority of the population, especially in Africa. To this end, they are a force for mobilization and work. Therefore, including them in all initiatives is not only a duty, but an important asset to increase development actions and ensure their sustainability.

- Strengthen the protection of the environment.

All development initiatives and actions depend on the stability of the environment. The fight against climate change and the protection of the environment in a comprehensive manner is an essential link for the achievement of all the objectives of sustainable development.

\section{CONCLUSION}

Covid-19 has revealed the dependence of the European economy on China and has fueled relocation attempts. This prospect will provide Tunisia as a privileged partner of Europe. Tunisian industry can therefore move to the high-end market, especially in biotechnology, IT development and renewable energy.

In terms of health, the poor are already the most vulnerable group: they are less resistant to disease, and their economic and social conditions provide them less protection. However, we must also consider the indirect impact of this crisis on the economy, education and future social relations

At the macro level, the paradox is that it is the most powerful and wealthy countries that are most affected. If you look closely, the five permanent members of the UN Security Council have been hit particularly hard. But in these countries, the most vulnerable are the most vulnerable.

Due to containment measures taken around the world, the global economy has fallen into crisis. According to current estimates, the worst economic crisis in history. Global GDP is expected to fall by 3.2\% in 2020 .

Indeed, it must be understood that when we talk about an economic crisis, it is actually a crisis, the consequences of which go far beyond simple economic and financial indicators. After all, the economy is the core of our society. When the economy is not good, all aspects of social life are often deteriorating.

For example, when an economic crisis breaks out, we often see rising unemployment, instability and poverty. The affected population then saw their living conditions deteriorate. Of course, there will be direct consequences: stress, fear of the future. However, we have also observed many indirect health consequences: poverty increases the risk of malnutrition or health risk behaviors (smoking, alcohol abuse). The poor are often forced to postpone health expenditures. They sometimes suffer from poor housing or insufficient fuel.

This health crisis has pushed back the achievement of the 17 sustainable development goals, essentially objective 1 (no poverty), objective 2 (zero hunger), objective 3 (health and well- being, objective 4 (education quality), Goal 7 (clean energy) and Goal 8 (decent work).

This crisis has also shown us that regardless of the country, rich or poor, it cannot escape the consequences of a pandemic and that the strong economic growth of a country cannot reflect the well-being of its people.

As a lesson learned, alongside the obstacles and shortcomings to be overcome, we must move towards a sovereign and sustainable development model, towards an ecological transition, towards the development of green technologies and more rational modes of production and consumption of water and in energy, a less polluting mode and more respectful of the rights of future generations

A more equitable model based on the spirit of solidarity between social economy and citizens and between regions.

Models or companies that guarantee the sustainability of profits must be environmentally and socially responsible.

Finally, this crisis shows that the world needs responsible economic operators, responsible nations and responsible partnerships to support the quality of human life and the protection of the planet.

The Secretary-General of the Tunis-Africa Business Council stated that reconstruction after COVID-19 needs to strengthen the digital transition according to the development situation, and protect the computer systems and databases of the country, banks and companies. In addition to ensuring the minimum industrial needs, remote work can also be carried out.

It also recommends the development of financial services. Especially by promoting the creation of virtual banks and new technologies such as "blockchain". And the development of virtual currency direct payment platforms and mobile banking. 


\section{SOURCES OF FUNDING}

This research received no specific grant from any funding agency in the public, commercial, or not-for-profit sectors.

\section{CONFLICT OF INTEREST}

The author have declared that no competing interests exist.

\section{ACKNOWLEDGMENT}

None.

\section{REFERENCES}

[1] Breisinger, C., M. Thomas, and J. Thurlow. 2009. Social Accounting Matrices and Multiplier Analysis: An Introduction with Exercises. Food Security in Practice Technical Guide no. 5. Washington, D.C.: IFPRI.

[2] Bolivar J.G. (2008). Comment intégrer les questions d'environnement et de développement dans l'ensemble des méthodologies de la gestion de projet: une démarche conceptuelle orientée vers un modèle de la planification de projet basé sur l'approche cadre logique. Uqar

[3] GENDRON (2004), Développement Durable et Economie Sociale: Convergences et articulations.

[4] IACE (Institut Arabe des Chefs d'Entreprises). 2020. L'impact du covid19 sur les entreprises tunisiennes. Tunis: IACE

[5] Jean Yves Martin, Le développement durable: doctrines pratiques évaluations, (Rapport Brundtland P47), IRD éditions, Paris, 2002, P51

[6] Kamali, A., M. Karara, C. Breisinger, M. Raouf, and M. Wiebelt. forthcoming. COVID-19 and the Egyptian economy: Impact of slowing domestic activity on economic sectors, jobs, and households. MENA Regional Program Policy Note. Cairo: International Food Policy Research Institute.

[7] Koonin, L. M. (2020). Novel coronavirus disease (COVID-19) outbreak: Now is the time to refresh pandemic plans. Journal of Business Continuity \& Emergency Planning, 13(4), 1-15.

[8] Mahler, D.G., C. Lakner, R.A. Castaneda Aguilar, and H. Wu. 2020. The impact of COVID-19 (Coronavirus) on global poverty: Why Sub-Saharan Africa might be the region hardest hit. Washington, DC: International Monetary Fund.

[9] McKibbin, W., \& Fernando, R. (2020). The global macroeconomic impacts of COVID-19: Seven scenarios (No. 2020-19). Centre for Applied Macroeconomic Analysis, Crawford School of Public Policy, The Australian National University.

[10] Notre avenir à tous, Commission mondiale pour l'environnement et le développement, édition du fleuve, publications du Québec, 1987, p.10

[11] Paolo Baracchini, guide a la mise en place du management environnemental en entreprise selon ISO 14001, 3eme édition, Presses Polytechniques et Universitaires Romandes, 2007, P9

[12] Round, J. 2003. “Social accounting matrices and SAM-based multiplier analysis.” In: Techniques and Tools for Evaluating the Poverty Impact of Economic Policies, Bourguignon F. and L. A. Pereira da Silva, eds. Washington, D.C. and Oxford: World Bank and Oxford University Press.

[13] Thurlow, J. 2020. A standard multiplier model for COVID-19 assessments. Unpublished SAM multiplier model (available upon request). Washington, DC: International Food Policy Research Institute.

[14] World Bank. 2020. Tunisia COVID-19 response project. Washington, DC: World Bank. https://projects.worldbank.org/en/projects-operations/project- detail/P173945?lang=en\&tab=overview, accessed April 27, 2020

[15] Banque Centrale de Tunisie

[16] INS (2020)

[17] FMI (2020) 